\title{
A Structural MRI Study of Human Brain Development from Birth to 2 Years
}

\author{
Rebecca C. Knickmeyer, ${ }^{1}$ Sylvain Gouttard, ${ }^{2}$ Chaeryon Kang, ${ }^{3}$ Dianne Evans, ${ }^{1}$ Kathy Wilber, ${ }^{4}$ J. Keith Smith, ${ }^{4}$ \\ Robert M. Hamer, ${ }^{1,3}$ Weili Lin, ${ }^{4}$ Guido Gerig, ${ }^{2}$ and John H. Gilmore ${ }^{1}$ \\ ${ }^{1}$ Department of Psychiatry, University of North Carolina, Chapel Hill, North Carolina 27599-7160, ${ }^{2}$ Scientific Computing and Imaging Institute, University \\ of Utah, Salt Lake City, Utah 84112, ${ }^{3}$ Department of Biostatistics, University of North Carolina, Chapel Hill, North Carolina 27599-7420, and ${ }^{4}$ Department of \\ Radiology, University of North Carolina, Chapel Hill, North Carolina 27599-7510
}

Brain development in the first 2 years after birth is extremely dynamic and likely plays an important role in neurodevelopmental disorders, including autism and schizophrenia. Knowledge regarding this period is currently quite limited. We studied structural brain development in healthy subjects from birth to 2. Ninety-eight children received structural MRI scans on a Siemens head-only 3T scanner with magnetization prepared rapid gradient echo T1-weighted, and turbo spin echo, dual-echo (proton density and T2 weighted) sequences: 84 children at $2-4$ weeks, 35 at 1 year and 26 at 2 years of age. Tissue segmentation was accomplished using a novel automated approach. Lateral ventricle, caudate, and hippocampal volumes were also determined. Total brain volume increased $101 \%$ in the first year, with a $15 \%$ increase in the second. The majority of hemispheric growth was accounted for by gray matter, which increased $149 \%$ in the first year; hemispheric white matter volume increased by only $11 \%$. Cerebellum volume increased $240 \%$ in the first year. Lateral ventricle volume increased $280 \%$ in the first year, with a small decrease in the second. The caudate increased $19 \%$ and the hippocampus $13 \%$ from age 1 to age 2. There was robust growth of the human brain in the first two years of life, driven mainly by gray matter growth. In contrast, white matter growth was much slower. Cerebellum volume also increased substantially in the first year of life. These results suggest the structural underpinnings of cognitive and motor development in early childhood, as well as the potential pathogenesis of neurodevelopmental disorders.

Key words: brain development; cortex; children; magnetic resonance imaging; hippocampus; caudate

\section{Introduction}

Quantitative magnetic resonance imaging has significantly advanced our understanding of brain development during childhood and adolescence. Several large scale longitudinal studies have been published (Giedd et al., 1999; Sowell et al., 2004). However, none of these large scale studies included children below the age of 4 years. This represents a serious gap in current knowledge, as these early years, particularly the period from birth to 2 , may be the most dynamic and important phase of postnatal brain development in humans. This period is likely to be critical in neurodevelopmental disorders including autism and schizophrenia. There is a dramatic increase in overall brain size during this period, with the brain reaching $80-90 \%$ of adult volume by age 2 (Pfefferbaum et al., 1994). The rapid elaboration of new synapses in the first two years of life (Huttenlocher and Dabholkar, 1997; Glantz et al., 2007) corresponds with an increase in

Received July 24, 2008; revised Sept. 24, 2008; accepted 0ct. 4, 2008.

This work was supported by National Institute of Mental Health Conte Center Grants MH064065 (J.H.G.), HD053000 (J.H.G.), HD03110 (G.G.), HD40127 (R.C.K.), and MH019111 (R.C.K). We thank Joe Blocher, Dr. Martin Styner, Dr. Liesa Glantz, Meghan Casey, Mike Graves, Rachel Gimpel-Smith, and Matthew Santelli for technical assistance and valuable discussions. We also thank the participating families who have made this project possible.

Correspondence should be addressed to John H. Gilmore, Department of Psychiatry, 7025 Neurosciences Hospital, Campus Box \#7160, University of North Carolina, Chapel Hill, NC 27599-7160. E-mail: jgilmore@med.unc.edu. DOI:10.1523/JNEUROSCI.3479-08.2008

Copyright $\odot 2008$ Society for Neuroscience $\quad 0270-6474 / 08 / 2812176-07 \$ 15.00 / 0$ overall gray matter volumes to a lifetime maximum around age 2 (Hüppi et al., 1998; Matsuzawa et al., 2001; Gilmore et al., 2007b). Myelination of white matter proceeds rapidly after birth. The general pattern of adult myelination is present by the end of the second year (Sampaio and Truwit, 2001), although myelination does continue, at a slower rate, far into adulthood. Concurrent with the rapid pace of structural brain development is an equally rapid development of a wide range of cognitive and motor functions (Kagan and Herschkowitz, 2005).

Most MRI studies of infants and young children have focused on those born prematurely (Hüppi et al., 1998; Peterson et al., 2003; Aljabar et al., 2008). Gray and white matter volume did increase significantly in the perinatal period in a small control group in two prospective studies of premature infants (Hüppi et al., 1998; Peterson et al., 2003). Another study including a few children under the age of $4-5$ also found that white and gray matter volume increased in the first few years of life, although the gray and white matter segmentation used in this study did not work well in younger subjects (Matsuzawa et al., 2001). This relative lack of data reflects the difficulties in performing MRI studies in infants and young children. Practical issues include subject cooperation and motion. Image analysis presents multiple challenges including low contrast to noise ratio, high variability and small size of anatomical shapes, rapid changes as a function of age, and contrast changes and brightness inhomogeneities attributable to myelination (Prastawa et al., 2005). 
Table 1. Distribution of scan availability

\begin{tabular}{lr}
\hline Available scans & $\mathrm{N}$ \\
\hline Neonate scan only & 50 \\
1 year scan only & 7 \\
2 year scan only & 1 \\
Neonate +1 year scan & 15 \\
Neonate +2 year scan & 12 \\
1 year +2 year scan & 6 \\
Neonate +1 year +2 year scan & 7
\end{tabular}

Our group is carrying out a large-scale, prospective, longitudinal MRI study of early brain development in a general population sample. This is the first developmental MRI study in this age range which utilizes a high-resolution 3 Tesla scanner and novel automatic methods for tissue segmentation and parcellation, which are highly accurate, reliable, and efficient (Hazlett et al., 2005; Prastawa et al., 2005; Gilmore et al., 2007b). We previously reported data on 74 neonates scanned at 2-4 weeks of age (Gilmore et al., 2007b). In the present study, we present initial results on structural brain development from birth to 2 years.

\section{Materials and Methods}

Subjects. The 98 children ( 49 male, 49 female; 82 White, 14 AfricanAmerican, 2 Asian) analyzed in this report are controls in an ongoing longitudinal study of prenatal and neonatal brain development in children at high risk for neurodevelopmental disorders. Control mothers were recruited during the second trimester of pregnancy from the outpatient Obstetrics and Gynecology Clinics at the University of North Carolina (UNC) Hospitals. Exclusion criteria at recruitment were the presence of abnormalities on fetal ultrasound or major medical or psychotic illness in the mother. 153 children attended for MRI at 2-4 weeks of age; 94 of these had high quality T1 and T2 scans (a success rate of $60 \%$ ). Eighty-six children attended for a follow-up MRI at age 1; 42 of these had high quality T1 and T2 scans (a success rate of 50\%). Sixtyseven children attended for a follow-up MRI at age 2; 35 of these have high quality T1 and T2 scans (a success rate of 50\%). Additional exclusion criteria for this analysis included gestational age $<34$ weeks $(n=2)$, spending $>24 \mathrm{~h}$ in the neonatal intensive care unit after birth $(n=7)$, a composite score of $<71$ on the Mullen scales of early development (Mullen, 1995) at either age 1 or age $2(n=3)$, major congenital abnormality $(n=0)$, history of major medical illness $(n=1)$, and major abnormality on MRI $(n=4)$. Twenty-three subjects had small incidental intracranial hemorrhages, which are present in $\sim 25 \%$ of vaginal births (Looney et al., 2007); these subjects are included in the analysis. Two children had febrile seizures; these subjects are also included in the analysis. After applying the above exclusion criteria, high quality scans are available for 84 neonates (2-4 weeks of age), 35 one year olds, and 26 two year olds. The sample is largely cross-sectional (Table 1); thus, when interpreting our results the possibility of cohort effects should be kept in mind. Written informed consent was obtained from a parent before participation. This study was approved by the Institutional Review Board of the University of North Carolina School of Medicine. Demographic data on the sample is found in Table 2.

Image acquisition. Magnetic resonance imaging was performed at the UNC MRI Research Center on a Siemens head-only 3T scanner (Allegra; Siemens Medical System). All subjects were studied without sedation. Neonates fell asleep easily after being fed and swaddled regardless of the time of day. Subjects at 1 and 2 years were mildly sleep deprived (i.e., parents were asked to wake the child $1 \mathrm{~h}$ early that day and to skip a nap). Scans were scheduled to coincide with the child's normal naptime or bedtime. Once a child was asleep, they were fitted with earplugs or earphones and placed in the MRI scanner with head in a Vac-Fix immobilization device, and additional foam padding to diminish the sounds of the scanner. Neonatal scans were performed with a neonatal nurse present and a pulse oximeter was used to monitor heart rate and oxygen
Table 2. Demographic data for participants

\begin{tabular}{lc}
\hline Factor & Mean (SD) \\
\hline Gestational age at birth (weeks) & $39.53(1.30)$ \\
Age at scan 1 (months) & $0.75(0.31)$ \\
Age at scan 2 (months) & $12.75(0.71)$ \\
Age at scan 3 (months) & $24.79(0.67)$ \\
Birth weight (g) & $3428.74(486.65)$ \\
Maternal education (total in years) & $15.74(3.05)$ \\
Total household income & $66,361.18(49,867.30)$
\end{tabular}

saturation. For older children, a member of the research team remained in the scanner room to monitor the child throughout the scan.

For the majority of the scans, T1-weighted images were obtained using a three-dimensional (3D) spoiled gradient [FLASH repetition time (TR)/ echo time (TE)/Flip Angle $15 / 7 \mathrm{~ms} / 25^{\circ}$. Fifteen of the early neonatal scans used a 3D magnetization prepared rapid gradient echo (TR/inversion time (TI)/TE/Flip Angle 1820/400/4.38 ms/7º T1 sequence. Proton density and T2-weighted images were obtained with a turbo spin echo (TR/TE1/TE2/Flip Angle 6200/20/119 ms/150 ${ }^{\circ}$. Spatial resolution was $1 \times 1 \times 1 \mathrm{~mm}$ voxel for T1-weighted images and $1.25 \times 1.25 \times 1.5 \mathrm{~mm}$ voxel with $0.5 \mathrm{~mm}$ interslice gap for proton density/T2-weighted images. The Siemens head-only 3T scanner is FDA approved for use in all age groups. Specific absorption rates are kept within safe levels for body weight by both hardware and software features of the scanner. We have previously confirmed that the scan sequences did not cause significant temperature increases with a phantom (Gilmore et al., 2004).

Tissue segmentation: neonates. Brain tissue was classified as gray matter, nonmyelinated white matter, myelinated white matter and CSF using an automatic, atlas-moderated expectation maximization segmentation tool as previously described (Prastawa et al., 2005; Gilmore et al., 2007b). Segmentations for 4 of the 84 scans collected in neonates were deemed poor quality. These scans were not included in the analysis of tissue volumes, but are included in the analysis of ventricle volume.

Tissue segmentation: age 1 and 2. The 1-year-old brain presents a unique set of challenges for tissue segmentation as white matter is inhomogeneous and provides high contrast interiorly while presenting gradually lower contrast toward the cortical periphery. In addition, white matter contrast in $\mathrm{T} 2$ lags behind $\mathrm{T} 1$, reflecting different properties of the early developing brain. To address this, we used a newly developed method for correction of white matter inhomogeneity as a preprocessing for classification of gray and white matter. Only the T1 image was used for segmentation. We used a well established automatic brain tissue segmentation method (expectation maximization segmentation) which integrates bias correction, brain stripping, and tissue classification into one tool (Van Leemput et al., 1999; Prastawa et al., 2004). A probabilistic infant brain atlas serves as geometric prior. The same method was used to segment the 2-year-old brain.

All scans were reviewed by an anatomical expert to determine if the results of the tissue segmentation were accurate. Segmentations for 5 of the 35 scans collected at age 1 were deemed poor quality. These scans were not included in the analysis of tissue volumes but are included in the analysis of ventricle, hippocampal, and caudate volumes.

Parcellation. Parcellation of each subject's brain into regions was achieved in the neonate by nonlinear warping of a parcellation atlas template as previously described (Hazlett et al., 2005; Gilmore et al., $2007 \mathrm{~b}$ ). An affine registration was used in the 1 and 2 year olds. Left and right hemispheres, cerebellum, brainstem and combined sets of subcortical structures are represented separately.

Subcortical structures. Measurement of the lateral ventricles at all ages, and measurement of the caudate and hippocampus at age 1 and age 2, were obtained using standardized tracing protocols. The lateral ventricles and caudate were defined on high resolution T1 images using a semiautomated 3D segmentation tool [ITK-SNAP (Yushkevich et al., 2006)] that employs a user-defined threshold window, initialization, and parameters for 3D deformable segmentation based on level sets. The hippocampus was obtained using a semiautomated tool where the user defines landmarks, but the hippocampus is automatically segmented via a 
high-dimensional deformation of a shape template [MOJO (Csernansky et al., 1998; Joshi et al., 2004)]. A single rater performed all segmentations for a specific structure. For the lateral ventricles, intrarater reliability was 0.99 ; for the caudate, intrarater reliability was 0.93 ; and for the hippocampus, intrarater reliability was 0.95. All reliabilities are intraclass correlations.

Data analysis. For all comparisons of brain volumes between the three ages, we used a mixed model approach to repeated measures ANOVA or analysis of covariance using the method of restricted/residual maximum likelihood. We used an unstructured covariance matrix with sandwich (Empirical) estimation to model within-subject covariances. In this model, we examined the estimated changes over time. Also, the change from neonate to 1 year and change from 1 year to 2 years were compared to determine whether there were different growth rates. All statistical hypothesis tests were conducted at a significance level of 0.05 .

\section{Results}

Total brain volume and volumes of the cortical hemispheres, subcortical area, and cerebellum

Total brain volume (TBV) was calculated by combining total gray matter and total white matter as defined by the automatic tissue segmentation. TBV increased by $101 \%$ in the first year (95\% CI: 95-107\%) and by $15 \%$ in the second year $(95 \% \mathrm{CI}$ : $11-19 \%$ ) (Figs. 1, 2). To put this in context, TBV at $2-4$ weeks of age is $\sim 36 \%$ of adult volume; TBV at 1 year is $\sim 72 \%$ of adult volume, and TBV at 2 years is $\sim 83 \%$ of adult volume [Comparison to adult volumes is based on TBV of 58 healthy adults who served as controls in Lieberman et al. (2005). Adult subject characteristics are as follows: mean (SD) age, 25.6 (4.1) years; $64 \%$ male; $61 \%$ Caucasian, $28 \%$ of African descent, 3\% Hispanic, and 8\% Asian.]. The volume of the cortical hemispheres increased by $88 \%$ in the first year $(95 \% \mathrm{CI}$ : $83-94 \%)$ and by $15 \%$ in the second year (95\% CI: $11-19 \%)$. The volume of the subcortical area (including brainstem) increased by $130 \%$ in the first year $(95 \% \mathrm{CI}$ : $126-138 \%)$ and by $14 \%$ in the second year (95\% CI: 11-18\%). The cerebellum increased by a striking $240 \%$ from 2 weeks to 1 year (95\% CI: 228-253\%), and increased by $15 \%$ from 1 to 2 years of age (95\% CI: 10-19\%) (Table 3; Fig. 2).

Volumes can be normalized by TBV to calculate the ratio of tissue volumes and anatomical regions relative to the full brain. This allows one to identify regions experiencing particularly rapid or slow growth relative to the full brain. When normalized in this way, the subcortical region and cerebellum continued to show significant increases from birth to age 1, whereas the cortical hemispheres decreased as a proportion of TBV. Be-

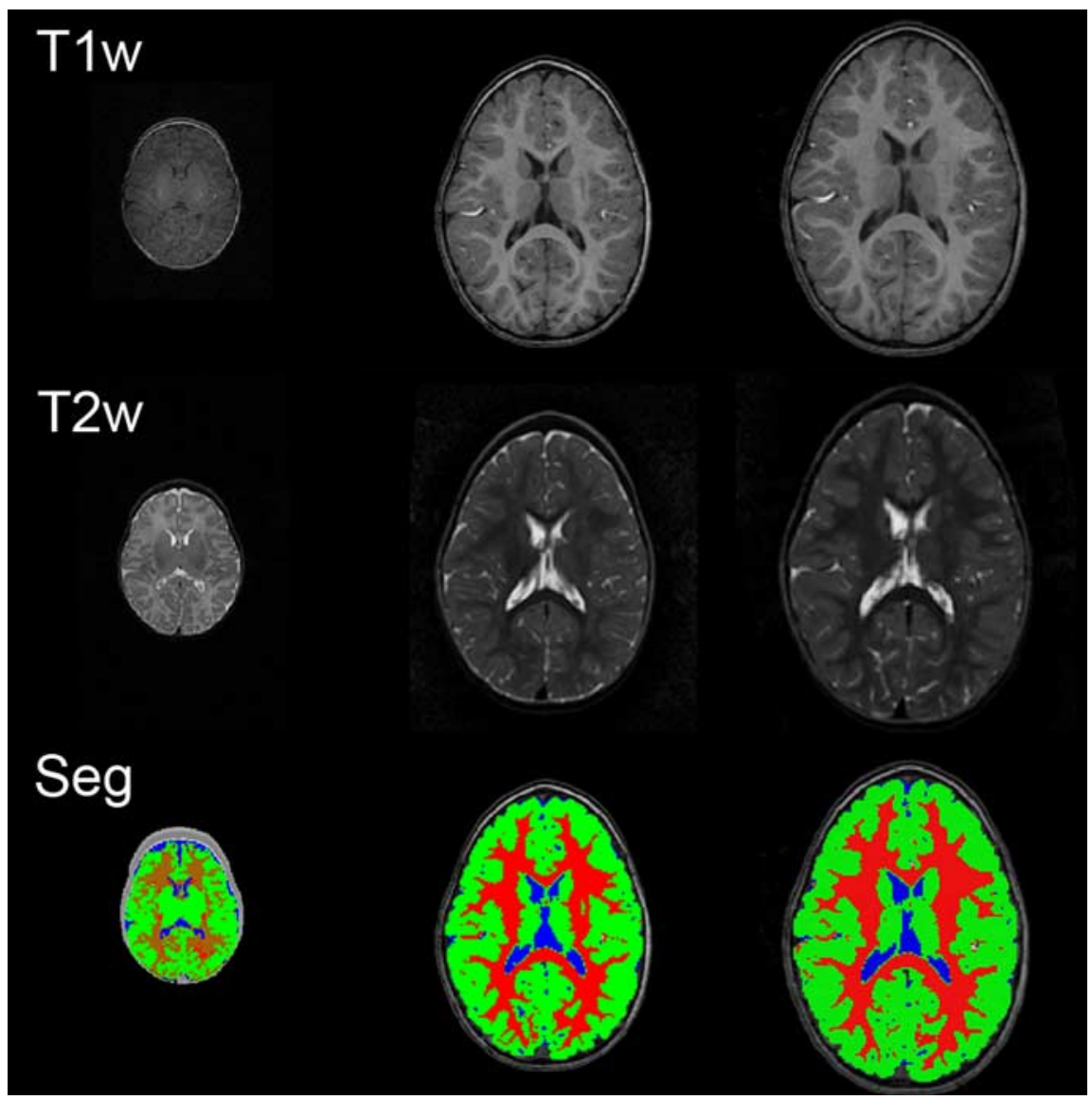

Figure 1. Example axial slices from a single subject at birth, 1, and 2 years. CSF (blue), GM (gray matter; green), myelinated WM (white matter; red), unmyelinated WM (brown).
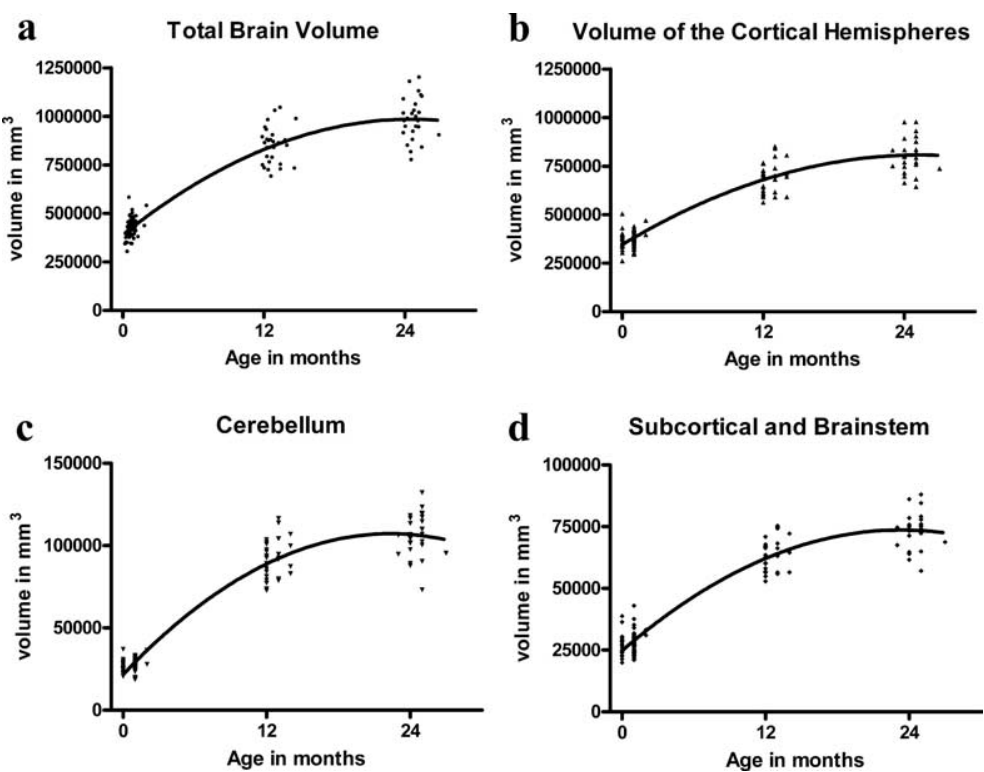

Figure 2. Scatterplots showing brain growth in the first 2 years of life. $\boldsymbol{a}$, Total brain volume by age at scan. $\boldsymbol{b}$, Cortical hemispheres. $\boldsymbol{c}$, Cerebellum. $\boldsymbol{d}$, Subcortical region and brainstem.

tween age 1 and age 2, only the cerebellum continued to show a significant increase when normalized for TBV. An alternative way of describing the relative growth of different regions is the correlation between growth in different regions in the subset of children with true longitudinal data. From age 0 to age 1 , the 
Table 3. Age-related changes in brain volumes

\begin{tabular}{|c|c|c|c|c|c|c|c|}
\hline \multirow[b]{2}{*}{ Region } & \multirow[b]{2}{*}{ Neonate } & \multirow[b]{2}{*}{1 year } & \multirow[b]{2}{*}{2 year } & \multicolumn{2}{|c|}{ Percentage change: $95 \% \mathrm{Cl}$ (neonate to 1 year) } & \multicolumn{2}{|c|}{ Percentage change: $95 \%$ Cl (1 year-2 year) } \\
\hline & & & & ANOVA & ANCOVA (adjusted for TBV) & ANOVA & ANCOVA (adjusted for TBV) \\
\hline TBV & $425,387(4806)$ & $855,540(12,492)$ & $983,866(15,393)$ & $95-107 \% *$ & N/A & $11-19 \% *$ & N/A \\
\hline Cerebral hemispheres & 370,685 (4185) & $699,378(10,199)$ & $804,501(12,577)$ & $83-94 \% *$ & -6 to $-5 \% *$ & $11-19 \% *$ & -1 to $1 \%$ \\
\hline Cerebellum & $26,985(371)$ & 91,962 (1712) & $105,154(2084)$ & $228-253 \% *$ & $71-83 \% *$ & $10-19 \% *$ & -1 to $9 \%^{\dagger}$ \\
\hline Subcortical + brainstem & $27,679(453)$ & $64,214(868)$ & $73,227(1140)$ & $126-138 \% *$ & $18-22 \% *$ & $11-18 \% *$ & -2 to $5 \%$ \\
\hline Hemispheric gray & $206,480(2396)$ & $514,048(6679)$ & $588,441(9100)$ & $143-155 \% *$ & $25-29 \% *$ & $11-18 \% *$ & $2-4 \%$ \\
\hline Hemispheric white & $164,433(1901)$ & $183,280(4122)$ & $217,883(5142)$ & $6-16 \% *$ & -60 to $-56 \% *$ & $13-24 \% *$ & -24 to $-4 \%^{\dagger}$ \\
\hline Lateral ventricles & $2109(149)$ & $8069(723)$ & $7406(786)$ & $213-352 \% *$ & -73 to $-22 \%$ & -28 to $11 \%$ & -160 to $-17 \% *$ \\
\hline Right caudate & N/A & $3221(69)$ & $3778(83)$ & $\mathrm{N} / \mathrm{A}$ & $\mathrm{N} / \mathrm{A}$ & $12-23 \% *$ & $1-11 \%^{\ddagger}$ \\
\hline Left caudate & $\mathrm{N} / \mathrm{A}$ & $3012(68)$ & 3607 (91) & $\mathrm{N} / \mathrm{A}$ & $\mathrm{N} / \mathrm{A}$ & $14-26 \% *$ & $3-15 \%{ }^{\ddagger}$ \\
\hline Right hippocampus & $\mathrm{N} / \mathrm{A}$ & $2113(39)$ & $2377(65)$ & $\mathrm{N} / \mathrm{A}$ & $\mathrm{N} / \mathrm{A}$ & $6-19 \%^{\dagger}$ & -4 to $7 \%$ \\
\hline Left hippocampus & $\mathrm{N} / \mathrm{A}$ & $2075(43)$ & $2367(68)$ & $\mathrm{N} / \mathrm{A}$ & $\mathrm{N} / \mathrm{A}$ & $7-21 \%^{\dagger}$ & -6 to $6 \%$ \\
\hline
\end{tabular}

All volumes are mean (SD) in $\mathrm{mm}^{3} .{ }^{*} p<0.0001,{ }^{\dagger} p<0.001,{ }^{\ddagger} p \leq 0.05$. N/A, Not applicable.

Cortical Gray and White Matter

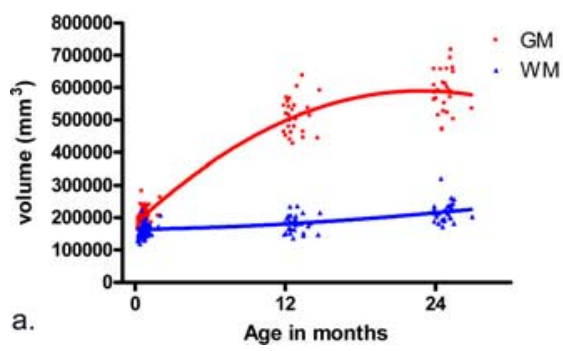

Figure 3. Gray and white matter growth in the first two years of life. $\boldsymbol{a}$, Scatterplot of absolute gray and white matter volumes by age at scan. $\boldsymbol{b}$, Scatterplot of gray and white matter volumes as a percentage of total brain volume.
Normalized Cortical Gray and White Matter

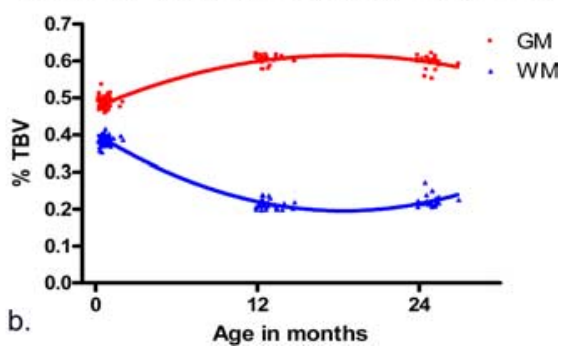

of $8 \%$ in the second year ( $95 \%$ CI: $28 \%$ decrease to $11 \%$ increase). However, when normalized for TBV, lateral ventricle volume decreased in both the first and second year. The caudate and hippocampus could not be reliably identified in the neonate, but total caudate volume increased by $19 \%$ between 1 and 2 years of age (95\% CI: $11-$ $26 \%)$; whereas total hippocampal volume increased by $13 \%$ (95\% CI: 7-20\%). When normalized for TBV, only caudate volume increased significantly between 1 and 2 years of age. Patterns were similar when left and right caudates and hippocampi were examined separately.

strongest correlation was seen between the cerebellum and the cortical hemispheres (Spearman correlation, 0.94; $\mathrm{N}=16$ ). Strong correlations were also seen between the subcortical area and the cortical hemispheres (Spearman correlation, 0.73) and between the subcortical area and the cerebellum (Spearman correlation, 0.68 ). From age 1 to age 2 , the strongest correlation was seen between the cerebellum and the subcortical region (Spearman correlation, $0.92 ; \mathrm{N}=9$ ). Strong correlations were also seen between the subcortical area and the cortical hemispheres (Spearman correlation, 0.82 ) and between the cortical hemispheres and the cerebellum (Spearman correlation, 0.85). These correlations are all large and not significantly different from each other.

\section{Constituent tissues}

Growth of the cortical hemispheres during this period appears to primarily reflect gray matter growth. Total hemispheric gray matter increased by $149 \%$ in the first year (95\% CI: $143-155 \%$ ) and by $14 \%$ in the second year (95\% CI: $11-18 \%)$. In contrast, total hemispheric white matter increased by $11 \%$ in the first year (95\% CI: $6-11 \%$ ) and by $19 \%$ in the second year (95\% CI: $13-$ $24 \%$ ). When normalized for TBV, the percentage of gray matter increased significantly in the first year and remained relatively constant in the second year. The percentage of white matter actually decreased in the first and second year. Thus, the ratio of hemispheric gray matter to white matter changes significantly in the first year, from 1.26 to 2.84 (Fig. 3). White matter and gray matter could not be accurately separated in the subcortical area and cerebellum by the automatic segmentation and are not reported.

\section{Subcortical structures}

The volume of the lateral ventricles increased $280 \%$ in the first year of life (95\% CI: $213-352 \%$ ), with a nonsignificant decrease
Although our sample size is not ideal for examining subsets of children, we did limited analyses on the effects of gender and ethnicity. Mean TBV was larger in males than females at all ages (95\% CI: $2-8 \% ; 3-13 \%$, and -1 to $8 \%$ for neonate, age 1 , and age 2 , respectively). This difference is slightly lower that that observed for ICV in neonates, 9\% (Gilmore et al., 2007b), and adults, 11.9-14.6\% (Gur et al., 1999; Raz et al., 2004). Growth patterns across all regions and substructures appeared highly similar between the genders, with the interesting exception of ventricular volume which dropped $1 \%$ between age 1 and age 2 in girls but dropped $24 \%$ in boys in the same period. This result must be treated with caution given the small sample size and high variability in ventricular volume. Results for all analyses were similar when we examined only those children who were white.

\section{Discussion}

The results of the present analysis confirm and significantly augment previous reports of early brain development in pediatric subjects. The large increase in total brain volume in the first year of life suggests that this is a critical period in which disruption of developmental processes, as the result of innate genetic abnormalities or as a consequence of environmental insults, may have long-lasting or permanent effects on brain structure and function. It is interesting to note that one of the most consistent anatomical findings in young children with autism is that they have larger-than-average heads (Bailey et al., 1993; Lainhart et al., 1997; Stevenson et al., 1997). Magnetic resonance imaging confirms that these large heads contain abnormally large brains, reflecting enlargement of gray and white matter (Courchesne et al., 2001; Hazlett et al., 2005). Retrospective analysis of head circumference data in medical records indicates that this difference emerges in the first year of life (Hazlett et al., 2005), the period of 
greatest brain volume growth in typical children. This suggests that the enlarged head size in children with autism may be an exaggeration of normal developmental processes in the first two years of life, such as synaptic proliferation and myelination. This period of rapid gray matter growth may also be important in the ultimate development of the abnormal cortical connectivity thought to underlie schizophrenia (Lewis and Levitt, 2002).

Although the first year of life may be a period of developmental vulnerability, it may also be a period in which therapeutic interventions would have the greatest positive effect. Relevant data are emerging from the Bucharest Early Intervention Project, which is following a cohort of Romanian children who were placed in foster care after experiencing extreme deprivation in orphanages. One of the surprising findings from this study is that children placed in foster care before two years of age appear to be making far better improvements in cognitive development than those placed in foster care after the age of 2 (Nelson et al., 2007). The profound changes in structural brain development we observed may delineate this critical period in cognitive development. Our results also suggest that there is a pressing clinical need to identify children at risk for developmental disorders within the first year of life and to initiate appropriate interventions.

Examination of constituent tissues in the cortical hemispheres suggests that early growth is driven primarily by gray matter. Although MRI is not currently capable of identifying the neurodevelopmental processes which underlie the observed volume changes, postmortem human and nonhuman primate studies reveal likely candidates. Although cells expressing markers which are characteristic of migrating neuroblasts and early neurons have been observed in the subventricular zone of human infants (Weickert et al., 2000), neurogenesis and neuronal migration are unlikely to account for the volume changes we observed as total cortical neuron numbers at 0,1 , and 2 years are highly similar (Shankle et al., 1999). It is more likely that the gray matter volume increase reflects changes in neuropil, which is composed of dendrites, axons, and glia. Intensive dendritic and axonal arborization and spine growth occur during this period (Mrzljak et al., 1990) and synaptic density also increases (Huttenlocher, 1979; Glantz et al., 2007). In the first two years, growth may be most pronounced in cortical layers II and III (Zecevic et al., 1989; Huttenlocher and Dabholkar, 1997; Landing et al., 2002).

As regards glia, a study of the striate cortex in rhesus monkeys showed a 10-fold increase in oligodendrocytes from birth to maturity. In contrast, the number of astrocytes and microglia appeared constant in early postnatal development (O'Kusky and Colonnier, 1982). The absolute increase in hemispheric white matter is likely to reflect myelination by oligodendrocytes; a process that will continue throughout childhood and adolescence and well into adulthood (Yakovlev and Lecours, 1967; Benes et al., 1994; Lenroot and Giedd, 2006). Increased volume attributable to myelination may be partially offset by axon elimination (LaMantia and Rakic, 1990; Low and Cheng, 2006). Although we have shown a striking difference in the developmental trajectories of hemispheric gray and white matter volume and significant changes in the ratio of gray to white matter during this period; this should not distract from the reciprocal relationships that exist between neurons, glia, and myelin. Within the developing nervous system, astrocytes and Schwann cells actively promote synapse formation and function (Allen and Barres, 2005), whereas neuron activity promotes the proliferation and survival of oligodendrocytes and the production of myelin (Simons and Trajkovic, 2006). The functional consequences of the dramatic change in the proportion of gray to white matter in the first year of life will be a fruitful area for future research using diffusion tensor imaging (DTI) and functional MRI. DTI has already shown striking changes in the corpus callosum and corticospinal tracts in the first 2 years of life (Gilmore et al., 2007a; Goodlett et al., 2008).

We observed a remarkable $240 \%$ increase in the size of the cerebellum in the first year. Although the relations between the size of brain structures and specific cognitive functions are not always clear, area size can influence performance of modalityspecific behaviors (Leingärtner et al., 2007). Because the cerebellum is critically involved in motor coordination and balance (Bastian and Thach, 2002), the striking cerebellar growth may underpin the rapid motor developments of infancy. The cerebellum has also been implicated in a plethora of other cognitive abilities including planning, set-shifting, language abilities, abstract reasoning, working memory, and visual-spatial organization (Schmahmann and Sherman, 1998). Given that "cognitive" regions of the cerebellum have reciprocal projections with nonprimary frontal, parietal, and occipital association cortex (Thach, 1996), the extremely rapid growth of the cerebellum in the first year may be a prerequisite for specific aspects of later cortical development. DTI and functional MRI studies of the developing connections between the cerebellum and the cortex may shed light on this relationship. As with the overall increase in brain size, the rapid growth of the cerebellum in the first year suggests that this may be a time of heightened vulnerability of the cerebellum, which shows preferential susceptibility to environmental insults such as alcohol, lead, and anoxia. Postnatal neurogenesis of cerebellar Purkinje cells may be related to this environmental susceptibility (Welsh et al., 2002), although the relationship between this process and the volumetric changes we observed remains to be clarified.

We also observed a large increase in the volume of the lateral ventricles in the first year, followed by a small decrease in volume in the second. It is unclear at this point how volume changes in the lateral ventricles relate to overall brain growth and the development of adjacent subcortical structures. We will explore these relationships in greater detail using shape analysis of the ventricles and surrounding structures. An antagonistic relationship between ventricles and subcortical nuclei is observed in certain pathological conditions, where atrophy of the basal ganglia or thalamus is associated with increased ventricular volume (Harris et al., 1999; Gaser et al., 2004). In addition, a study of monozygotic and dizygotic twins showed significant negative genetic and environmental correlations between lateral ventricle and basal ganglia volumes (Schmitt et al., 2007). It is not clear why ventricle volume would increase in the first year and decrease in the second year of life, given continued growth of subcortical and cortical structures. One possibility is that closure of the fontanelles (unossified gaps between the calvarial bones) limits outward growth of the brain in the second year, with growth now impinging on the lateral ventricles.

Finally, we reported that the caudate and hippocampus increased in volume from 1 to 2 years, but only the caudate increased when normalized for TBV. This suggests that different subcortical structures have different developmental trajectories during this period. The caudate is crucial in the control of movement (Herrero et al., 2002). Therefore, growth in this region may relate to motor development. The relatively small growth of the hippocampus may still have functional consequences for cognitive tasks linked to this structure, including spatial (Maguire et al., 1997) and episodic memory (Lencz et al., 1992; Goldberg et al., 1994). Although direct comparison to the single existing MRI 
study of early hippocampal growth is difficult because of differing methodologies, our results are broadly compatible with those of Utsunomiya et al. (1999) who report a 5\% difference in hippocampal volume when comparing children between 1 and 2 years of age with those between 3 and 4 years of age.

In conclusion, we observed rapid growth of the entire brain during the first year of life, with slower growth during the second year of life. Compared with the cortical hemispheres, the cerebellum showed disproportionate enlargement in this period. Within the cortical hemispheres, gray matter volume increased significantly more than white matter volume and the proportion of gray to white matter changed markedly. Unique growth patterns were also observed in the ventricles, caudate, and hippocampus. These findings can provide insight into pathologies of development such as autism and schizophrenia and may ultimately allow us to define structural correlates of critical periods in human cognitive development.

\section{References}

Aljabar P, Bhatia KK, Murgasova M, Hajnal JV, Boardman JP, Srinivasan L, Rutherford MA, Dyet LE, Edwards AD, Rueckert D (2008) Assessment of brain growth in early childhood using deformation-based morphometry. Neuroimage 39:348-358.

Allen NJ, Barres BA (2005) Signaling between glia and neurons: focus on synaptic plasticity. Curr Opin Neurobiol 15:542-548.

Bailey A, Luthert P, Bolton P, Le Couteur A, Rutter M (1993) Autism and megalencephaly. Lancet 341:1225-1226.

Bastian A, Thach WT (2002) Structure and function of the cerebellum. In: The cerebellum and its disorders (Manto M, Pandolfo M, eds), pp 49-66. Cambridge, UK: Cambridge UP.

Benes FM, Turtle M, Khan Y, Farol P (1994) Myelination of a key relay zone in the hippocampal-formation occurs in the human brain during childhood, adolescence, and adulthood. Arch Gen Psychiatry 51:477-484.

Courchesne E, Karns CM, Davis HR, Ziccardi R, Carper RA, Tigue ZD, Chisum HJ, Moses P, Pierce K, Lord C, Lincoln AJ, Pizzo S, Schreibman L, Haas RH, Akshoomoff NA, Courchesne RY (2001) Unusual brain growth patterns in early life of patients with autistic disorder. Neurology 57:245-254.

Csernansky JG, Joshi S, Wang L, Haller JW, Gado M, Miller JP, Grenander U, Miller MI (1998) Hippocampal morphometry in schizophrenia by high dimensional brain mapping. Proc Natl Acad Sci U S A 95:11406-11411.

Gaser C, Nenadic I, Buchsbaum BR, Hazlett EA, Buchsbaum MS (2004) Ventricular enlargement in schizophrenia related to volume reduction of the thalamus, striatum, and superior temporal cortex. Am J Psychiatry 161:154-156.

Giedd JN, Blumenthal J, Jeffries NO, Castellanos FX, Liu H, Zijdenbos A, Paus T, Evans AC, Rapoport JL (1999) Brain development during childhood and adolescence: a longitudinal MRI study. Nat Neurosci 2:861-863.

Gilmore JH, Zhai G, Wilber K, Smith JK, Lin W, Gerig G (2004) 3T magnetic resonance imaging of the brain in newborns. Psychiatry Res 132:8185.

Gilmore JH, Lin W, Corouge I, Vetsa YS, Smith JK, Kang C, Gu H, Hamer RM, Lieberman JA, Gerig G (2007a) Early postnatal development of corpus callosum and corticospinal white matter assessed with quantitative tractography. Am J Neuroradiol 28:1789-1795.

Gilmore JH, Lin W, Prastawa MW, Looney CB, Vetsa YS, Knickmeyer RC, Evans DD, Smith JK, Hamer RM, Lieberman JA, Gerig G (2007b) Regional gray matter growth, sexual dimorphism, and cerebral asymmetry in the neonatal brain. J Neurosci 27:1255-1260.

Glantz LA, Gilmore JH, Hamer RM, Lieberman JA, Jarskog LF (2007) Synaptophysin and postsynaptic density protein 95 in the human prefrontal cortex from mid-gestation into early adulthood. Neuroscience 149:582-591.

Goldberg TE, Torrey EF, Berman KF, Weinberger DR (1994) Relations between neuropsychological performance and brain morphological and physiological measures in monozygotic twins discordant for schizophrenia. Psychiatry Res 55:51-61.

Goodlett CB, Fletcher PT, Gilmore JH, Gerig G (2008) Group analysis of DTI fiber tract statistics with application to neurodevelopment. Neuroimage, in press.
Gur RC, Turetsky BI, Matsui M, Yan M, Bilker W, Hughett P, Gur RE (1999) Sex differences in brain gray and white matter in healthy young adults: Correlations with cognitive performance. J Neurosci 19:4065-4072.

Harris GJ, Codori AM, Lewis RF, Schmidt E, Bedi A, Brandt J (1999) Reduced basal ganglia blood flow and volume in pre-symptomatic, genetested persons at-risk for Huntington's disease. Brain 122:1667-1678.

Hazlett HC, Poe M, Gerig G, Smith RG, Provenzale J, Ross A, Gilmore J, Piven J (2005) Magnetic resonance imaging and head circumference study of brain size in autism - birth through age 2 years. Arch Gen Psychiatry 62:1366-1376

Herrero MT, Barcia C, Navarro JM (2002) Functional anatomy of thalamus and basal ganglia. Childs Nerv Syst 18:386-404.

Hüppi PS, Warfield S, Kikinis R, Barnes PD, Zientara GP, Jolesz FA, Tsuji MK, Volpe JJ (1998) Quantitative magnetic resonance imaging of brain development in premature and mature newborns. Ann Neurol 43:224-235.

Huttenlocher PR (1979) Synaptic density in human frontal-cortex developmental-changes and effects of aging. Brain Res 163:195-205.

Huttenlocher PR, Dabholkar AS (1997) Regional differences in synaptogenesis in human cerebral cortex. J Comp Neurol 387:167-178.

Joshi S, Davis B, Jomier M, Gerig G (2004) Unbiased diffeomorphic atlas construction for computational anatomy. Neuroimage 23:S151-S160.

Kagan J, Herschkowitz N (2005) A young mind in a growing brain. Mahwah, NJ: Erlbaum Associates.

Lainhart JE, Piven J, Wzorek M, Landa R, Santangelo SL, Coon H, Folstein SE (1997) Macrocephaly in children and adults with autism. J Am Acad Child Adolesc Psychiatry 36:282-290.

LaMantia AS, Rakic P (1990) Axon overproduction and elimination in the corpus-callosum of the developing rhesus-monkey. J Neurosci 10:2156-2175.

Landing BH, Shankle WR, Hara J, Brannock J, Fallon JH (2002) The development of structure and function in the postnatal human cerebral cortex from birth to 72 months: changes in thickness of layers II and III co-relate to the onset of new age-specific behaviors. Pediatr Pathol Mol Med 21:321-342.

Leingärtner A, Thuret S, Kroll TT, Chou SJ, Leasure JL, Gage FH, O’Leary DD (2007) Cortical area size dictates performance at modality-specific behaviors. Proc Natl Acad Sci U S A 104:4153-4158.

Lencz T, McCarthy G, Bronen RA, Scott TM, Inserni JA, Sass KJ, Novelly RA, Kim JH, Spencer DD (1992) Quantitative magnetic-resonance-imaging in temporal-lobe epilepsy - relationship to neuropathology and neuropsychological function. Ann Neurol 31:629-637.

Lenroot RK, Giedd JN (2006) Brain development in children and adolescents: Insights from anatomical magnetic resonance imaging. Neurosci Biobehav Rev 30:718-729.

Lewis DA, Levitt P (2002) Schizophrenia as a disorder of neurodevelopment. Annu Rev Neurosci 25:409-432.

Lieberman JA, Tollefson GD, Charles C, Zipursky R, Sharma T, Kahn RS, Keefe RS, Green AI, Gur RE, McEvoy J, Perkins D, Hamer RM, Gu H, Tohen M (2005) Antipsychotic drug effects on brain morphology in first-episode psychosis. Arch Gen Psychiatry 62:361-370.

Looney CB, Smith JK, Merck LH, Wolfe HM, Chescheir NC, Hamer RM, Gilmore JH (2007) Intracranial hemorrhage in asymptomatic neonates: prevalence on MR images and relationship to obstetric and neonatal risk factors. Radiology 242:535-541.

Low LK, Cheng HJ (2006) Axon pruning: an essential step underlying the developmental plasticity of neuronal connections. Philos Trans R Soc Lond B Biol Sci 361:1531-1544.

Maguire EA, Frackowiak RS, Frith CD (1997) Recalling routes around London: activation of the right hippocampus in taxi drivers. J Neurosci 17:7103-7110.

Matsuzawa J, Matsui M, Konishi T, Noguchi K, Gur RC, Bilker W, Miyawaki T (2001) Age-related volumetric changes of brain gray and white matter in healthy infants and children. Cereb Cortex 11:335-342.

Mrzljak L, Uylings HB, Van Eden CG, Judás M (1990) Neuronal development in human prefrontal cortex in prenatal and postnatal stages. Prog Brain Res 85:185-222.

Mullen EM (1995) Mullens scales of early development. In: American Guidance Service. Circle Pines, MN: American Guidance Service.

Nelson CA 3rd, Zeanah CH, Fox NA, Marshall PJ, Smyke AT, Guthrie D (2007) Cognitive recovery in socially deprived young children: the Bucharest early intervention project. Science 318:1937-1940. 
O'Kusky J, Colonnier M (1982) Postnatal Changes in the number of astrocytes, oligodendrocytes, and microglia in the visual-Cortex (area-17) of the macaque monkey - a stereological analysis in normal and monocularly deprived animals. J Comp Neurol 210:307-315.

Peterson BS, Anderson AW, Ehrenkranz R, Staib LH, Tageldin M, Colson E, Gore JC, Duncan CC, Makuch R, Ment LR (2003) Regional brain volumes and their later neurodevelopmental correlates in term and preterm infants. Pediatrics 111:939-948.

Pfefferbaum A, Mathalon DH, Sullivan EV, Rawles JM, Zipursky RB, Lim KO (1994) A quantitative magnetic-resonance-imaging study of changes in brain morphology from infancy to late adulthood. Arch Neurol 51:874-887.

Prastawa M, Bullitt E, Ho S, Gerig G (2004) A brain tumor segmentation framework based on outlier detection. Med Image Anal 8:275-283.

Prastawa M, Gilmore JH, Lin W, Gerig G (2005) Automatic segmentation of MR images of the developing newborn brain. Med Image Anal 9:457-466.

Raz N, Gunning-Dixon F, Head D, Rodrigue KM, Williamson A, Acker JD (2004) Aging, sexual dimorphism, and hemispheric asymmetry of the cerebral cortex: replicability of regional differences in volume. Neurobiol Aging 25:377-396.

Sampaio RC, Truwit CL (2001) Myelination in the developing brain. In: Handbook of developmental cognitive neuroscience (Nelson CA, Luciana $\mathrm{M}$, eds), pp 35-44. Cambridge, MA: MIT.

Schmahmann JD, Sherman JC (1998) The cerebellar cognitive affective syndrome. Brain 121:561-579.

Schmitt JE, Wallace GL, Rosenthal MA, Molloy EA, Ordaz S, Lenroot R, Clasen LS, Blumenthal JD, Kendler KS, Neale MC, Giedd JN (2007) A multivariate analysis of neuroanatomic relationships in a genetically informative pediatric sample. Neuroimage 35:70-82.

Shankle WR, Rafii MS, Landing BH, Fallon JH (1999) Approximate doubling of numbers of neurons in postnatal human cerebral cortex and in 35 specific cytoarchitectural areas from birth to 72 months. Pediatr Dev Pathol 2:244-259.

Simons M, Trajkovic K (2006) Neuron-glia communication in the control of oligodendrocyte function and myelin biogenesis. J Cell Sci 119:4381-4389.

Sowell ER, Thompson PM, Leonard CM, Welcome SE, Kan E, Toga AW (2004) Longitudinal mapping of cortical thickness and brain growth in normal children. J Neurosci 24:8223-8231.

Stevenson RE, Schroer RJ, Skinner C, Fender D, Simensen RJ (1997) Autism and macrocephaly. Lancet 349:1744-1745.

Thach WT (1996) On the specific role of the cerebellum in motor learning and cognition: clues from PET activation and lesion studies in humans. Behav Brain Sci 19:411-431.

Utsunomiya H, Takano K, Okazaki M, Mitsudome A (1999) Development of the temporal lobe in infants and children: analysis by MR-based volumetry. Am J Neuroradiol 20:717-723.

Van Leemput K, Maes F, Vandermeulen D, Suetens P (1999) Automated model-based bias field correction of MR images of the brain. IEEE Trans Med Imaging 18:885-896.

Weickert CS, Webster MJ, Colvin SM, Herman MM, Hyde TM, Weinberger DR, Kleinman JE (2000) Localization of epidermal growth factor receptors and putative neuroblasts in human subependymal zone. J Comp Neurol 423:359-372.

Welsh JP, Yuen G, Placantonakis DG, Vu TQ, Haiss F, O’Hearn E, Molliver ME, Aicher SA (2002) Why do Purkinje cells die so easily after global brain ischemia? Aldolase C, EAAT4, and the cerebellar contribution to posthypoxic myoclonus. Adv Neurol 89:331-359.

Yakovlev P, Lecours A (1967) The myelogenetic cycles of regional maturation of the brain. In: Regional development of the brain in early life (Minkowski A, ed), pp 3-70. Oxford: Blackwell.

Yushkevich PA, Piven J, Hazlett HC, Smith RG, Ho S, Gee JC, Gerig G (2006) User-guided 3D active contour segmentation of anatomical structures: Significantly improved efficiency and reliability. Neuroimage 31:1116-1128.

Zecevic N, Bourgeois JP, Rakic P (1989) Changes in synaptic density in motor cortex of rhesus-monkey during fetal and postnatal life. Brain Res Dev Brain Res 50:11-32. 